\title{
DESIGN OF A DAILY-USER METHODOLOGY TO DETECT FUEL CONSUMPTION IN CARS WITH SPARK IGNITION ENGINE
}

UDC: 621.43 .019

Original scientific paper

https://doi.org/10.18485/aeletters.2020.5.3.2

\author{
Tomas Skrucany $^{1 *}$, Maria Stopkova ${ }^{2}$, Ondrej Stopka ${ }^{2}$ and Saša Milojević ${ }^{3}$ \\ ${ }^{1}$ Department of Road and Urban Transport, University of Žilina, Žilina, Slovakia \\ ${ }^{2}$ Department of Transport and Logistics, Institute of Technology and Business in České Budějovice, České \\ Budějovice, Czech Republic \\ ${ }^{3}$ University of Kragujevac, Faculty of Engineering, Department for Motor Vehicles and IC Engines, Serbia
}

\begin{abstract}
:
The article focuses on detection of fuel consumption in cars with the sparkignition engine aiming to determine the most accurate way of daily-use fuel consumption through evaluation finding. To achieve relevant outcomes, different routes underwent experiments in multiple consumption modes. In particular, these encompass four circuits varying in length, speed limit, intersection number with significant waiting time and the route ratio city/highway. Each segment saw three measurings in terms of different consumption forms - standard, economical and dynamic. Apart from that, fuel consumption detection also takes into cosideration possible deviations from consumed fuel when automatically switching off the fuel pump pistol. Three methods contributed to achieving the findings; i.e. quantification method, the technique of data subtraction from the on-board computer (On-Board Unit) and method of amassing data from a phone application. Ultimately, compiled tables and detailed diagrams show outcomes demonstrating the most convenient way and approach of measuring fuel consumption for daily-users.
\end{abstract}

ARTICLE HISTORY Received: 09.07.2020. Accepted: 20.08.2020. Available: 30.09 .2020 .

\section{KEYWORDS}

Fuel consumption detection, passenger car, spark ignition engine, daily user, measurement technique

\section{INTRODUCTION}

Fuel consumption represents an important indicator of road motor vehicles in terms of its economy [1], technical condition [2] and exhaust gases emission [3-5], and requires careful monitoring. Fuel consumption varies according to the vehicle technical state [2], which makes technical certificate data insufficient calling for a regular check-up [6].

There are various methods of detecting fuel consumption available to daily-users. Firstly, it is a technique of subtracting data from the board computer or a simple quantification or an application to indicate fuel consumption. All these suggested methods accommodate daily-users, however not considering specific deviations that may occur (i.e. discrepancies in the amount of consumed fuel when automatically switching off the pump pistol) [6].

The manuscript aims at suggesting a convenient method of reliably detecting fuel consumption in cars with spark ignition (SI) engine for daily-users. The methodology disregards laboratory technologies, however respecting common factors affecting the very fuel consumption [7].

\section{DATA AND METHODS}

With the intent to suggest the most reliable technique measuring fuel consumption in normal conditions [8], the individual steps were followed (Fig.1). As for the examination itself, we chose AUDI S5 passenger car SI engine. Fuel consumption 
varies depending on specific circumstances. Therefore, the producer suggests three different consumption values based on the New European Driving Cycle (NEDC): urban operation consumption $18.1 \mathrm{l} / 100 \mathrm{~km}$, extra-urban operation consumption $8.7 \quad \mathrm{l} / 100 \mathrm{~km}$ and combined consumption $12.1 \mathrm{l} / 100 \mathrm{~km}$.

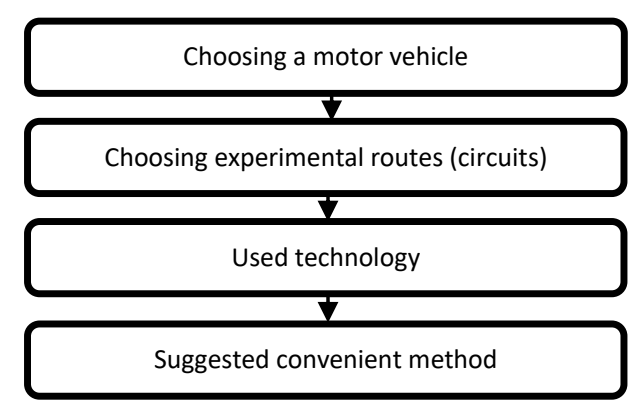

Fig. 1. Individual steps of the measuring technique. Source: authors

To this end, we chose four experimental segments of different parameters to achieve accurate research results [9]. The length of the route section (i.e. distance traveled) is the key parameter affecting the fuel consumption. In addition, individual routesections are highly specific about being situated either in the city or outside, which means further parameter involvement; the speed limit, intersection number and the city/highway ratio [10]. Table 1 summarizes individual specifications of certain routes.

Table 1. Specifications of selected routes. Source: authors

\begin{tabular}{|c|c|c|c|c|c|}
\hline & 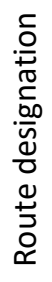 & 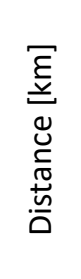 & 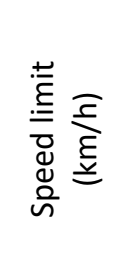 & 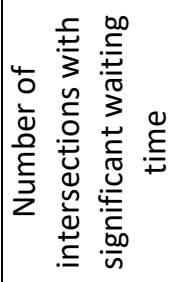 & 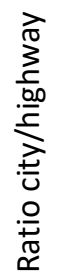 \\
\hline \multirow{2}{*}{ 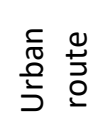 } & 1 & 3.9 & $50-70$ & 2 & - \\
\hline & 2 & 8.8 & $50-80$ & 1 & - \\
\hline \multirow{2}{*}{ 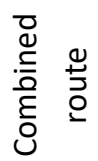 } & 3 & 32.5 & $50-130$ & 1 & $1: 1$ \\
\hline & 4 & 61.7 & $50-130$ & - & $1: 3$ \\
\hline
\end{tabular}

The measuring process of fuel filled at the petrol station requires sophisticated technology [11]. For these purposes, the experiment used densimeters, a digital scale for gauging fuel density and weight, jerricans, a specially modified fuel filler neck of which the intent was to adjust the filling pistol and wireless adapters for detecting consumption [12].

Before the very fuel consumption investigation, measurements of deviations were needed to be carry out. Each measurement was executed on the same pump stand and by the same pump pistol with the aim to eliminate deviations which may occur due to using multiple fuel pump pistols [13].

Each investigation was performed three times on each route section. Each route section was accomplished under various driving technique; economical, then regular and finally dynamic technique of driving. Thereafter, the next investigation was realized once on all the route sections only under regular technique of driving. Fuel was added almost to the edge of the fuel tank neck [14].

A designed flowchart of the fuel consumption examination process is depicted in Fig.2.

Detecting a deviation between the amount of fuel filled at the specific pump of the petrol station and the amount actualy measured.

Detecting a deviation between the amount of filled fuel when automatically switching off the pistol.

Detecting the fuel level in the tank - the state after the pistol was switched off for the first time.

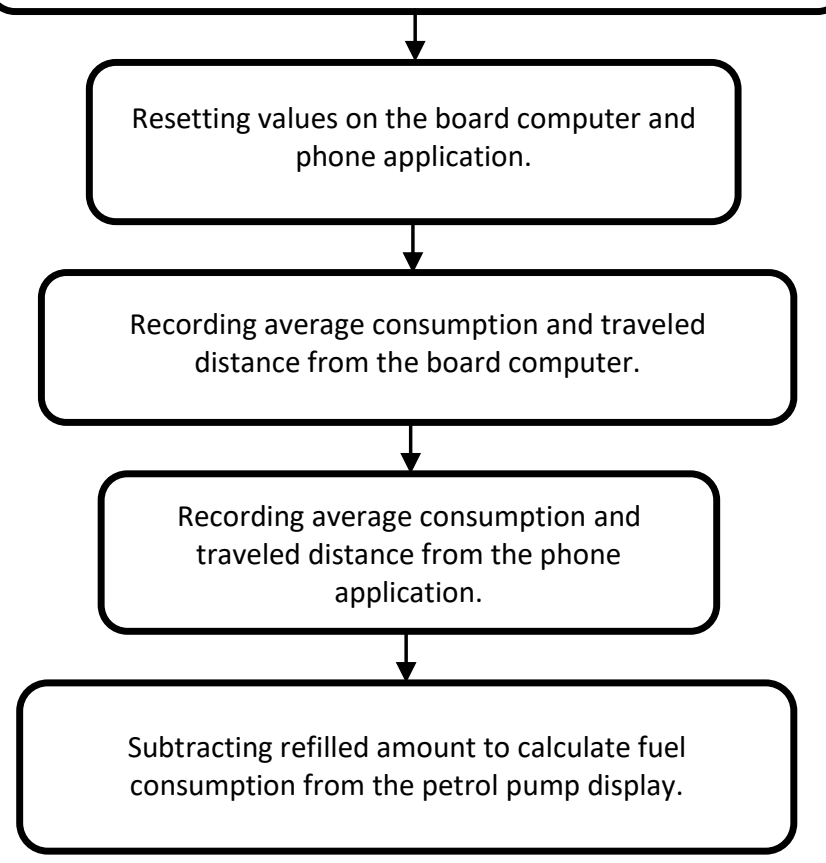

Fig. 2. The methodology of the fuel consumption detection. Source: authors 


\section{ACHIEVED RESULTS}

At the beginning of the detection procedure, the quantified standard value of fuel consumption was stipulated to be a initial value. Based on this value, other types of consumption investigation were then compared [15].

\subsection{Accuracy and deviation examination of the amount of consumed fuel}

As far as the first investigation went, the maximum permissible error, in order to specify dispensed fuel accuracy, was obtained of (+/-) $0.5 \%$ of the dispensed quantity. In practice, this means of (+/-) 0.1 I per 20 I of filled fuel.

The very fuel consumption examination was conducted by obtaining fuel weight values detected at laboratory scales and fuel quantity dispensed at the fuel station [16]. Such values were compared with quantified values (based on the detected weight and fuel density). In the following table (see Table 2), all the measured deviations are listed.

Table 2. Accurate numbers of consumed fuel at petrol pump (Petrol 95 octane). Source: authors

\begin{tabular}{|c|c|c|c|c|c|c|}
\hline 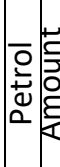 & 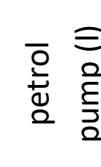 & $\begin{array}{l}\frac{000}{0} \\
\frac{n}{5} \\
\frac{.00}{01} \\
3\end{array}$ & 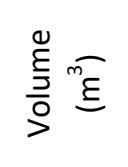 & 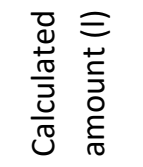 & 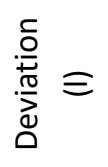 & 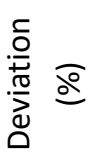 \\
\hline & 5.03 & 3770.2 & 0.00498 & 4.98044 & 0.0496 & 0.99 \\
\hline & 10.33 & 7741.4 & 0.01022 & 10.22642 & 0.1036 & 1.01 \\
\hline & 5.11 & 3833.9 & 0.00506 & 5.06459 & 0.0454 & 0.90 \\
\hline & 10.47 & 7848.5 & 0.01036 & 10.36789 & 0.1021 & 0.98 \\
\hline \multicolumn{5}{|c|}{$\varnothing$ deviation } & 0.0752 & 0.97 \\
\hline
\end{tabular}

The second measurement focused on detecting the deviation of filled fuel caused by the pump pistol switch-off. For this purpose, we used a fuel filler neck of Škoda Felicia with the adjustment to fully adapt to the vehicle position so that the experiment proceeds in the same position.

Overall, we conducted 9 measurements and achieved 9 values of refilled fuel (from 0.87 to 0.94 I). Values were subsequently set out as follows:

- mean with the value of $0.9055 \mathrm{I}$,

- standard deviation with the value of $0.02297 \mathrm{I}$, - the deviation caused by the pump pistol switchoff, of which the value may equal to $0.07 \mathrm{I}$.

\subsection{Fuel consumption detection}

First of all, we refilled fuel no sooner than after the pump pistol had switched off. The procedure began by resetting measured values of consumed fuel and traveled distance on the board computer (referred to as PC) and specific smartphone application. Experimental routes consecutively saw an economical, standard and dynamic driving technique [17].

The examining process involved OBD apps data (or Torque) along with Vgate iCar Pro Wifi Adapter. Table 3 lists findings of the first experiment.

Table 3. Results of the first investigation of fuel consumption of $\mathrm{SI}$ engine. Source: authors

\begin{tabular}{|c|c|c|c|c|c|c|c|c|}
\hline$i^{\circ}$ & 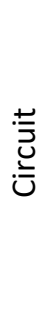 & 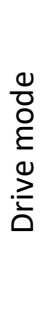 & 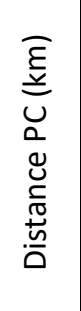 & 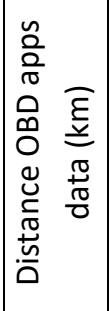 & 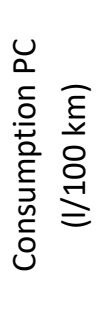 & 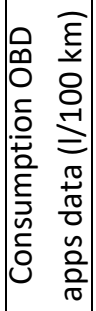 & 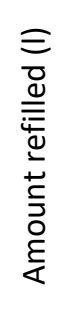 & 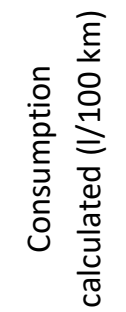 \\
\hline 1 & 1 & $E$ & 3.8 & 3.77 & 13.0 & 9.5 & 1.45 & $38.158 *$ \\
\hline 2 & 1 & $S$ & 3.9 & 3.85 & 15.6 & 14.7 & 1.05 & $26.923 *$ \\
\hline 3 & 1 & $D$ & 3.9 & 3.82 & 18.8 & 20.1 & 1.18 & $30.256^{*}$ \\
\hline 4 & 2 & $E$ & 8.8 & 8.69 & 10.2 & 10.6 & 1.06 & 12.045 \\
\hline 5 & 2 & $S$ & 8.8 & 8.69 & 11.6 & 11.9 & 1.12 & 12.727 \\
\hline 6 & 2 & $\mathrm{D}$ & 8.8 & 8.69 & 14.6 & 14.2 & 1.32 & 15.000 \\
\hline 7 & 3 & $E$ & 31.9 & 31.57 & 9.5 & 9.7 & 2.97 & 9.310 \\
\hline 8 & 3 & $S$ & 31.9 & 31.57 & 11.2 & 11.5 & 3.78 & 11.850 \\
\hline 9 & 3 & $\mathrm{D}$ & 31.9 & 31.57 & 13.5 & 12.7 & 4.28 & 13.417 \\
\hline 10 & 4 & $E$ & 57.7 & 57.01 & 9.4 & 10.1 & 5.82 & 10.087 \\
\hline 11 & 4 & $S$ & 57.6 & 57.06 & 11.2 & 11.3 & 6.71 & 11.649 \\
\hline 12 & 4 & $\mathrm{D}$ & 57.6 & 56.95 & 15.6 & 14.9 & 8.97 & 15.573 \\
\hline
\end{tabular}

The next measurement method of fuel consumption focuses on refilling fuel up to a specific point. This point almost reaches the tank lid, allowing an easy visual accuracy check. These experiments were conducted on all the route sections.

Table 4 shows the results of the second experimental detection of fuel consumption.

This experiment investigates the first route section twice. The whole process had to be repeated with the intent to remove potential air bubbles in the tank since it was almost empty before the measuring took place. 
Table 4. The results of the second investigation of fuel consumption of SI engine. Source: authors

\begin{tabular}{|c|c|c|c|c|c|c|c|c|}
\hline ì & 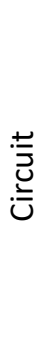 & 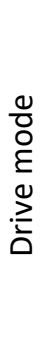 & 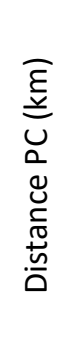 & 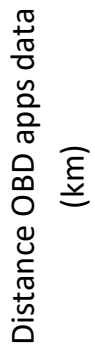 & 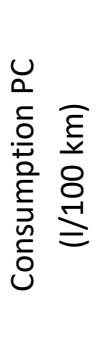 & 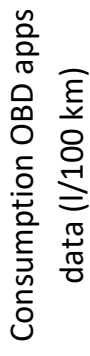 & 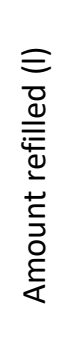 & 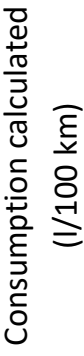 \\
\hline 1 & 1 & $S$ & 3.9 & 3.81 & 14.3 & 13.7 & 0.99 & 25.38 \\
\hline 2 & 1 & 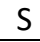 & 3.9 & 3.81 & 12.7 & 12.3 & 0.79 & 20.26 \\
\hline 3 & 2 & $\mathrm{~S}$ & 8.8 & 8.67 & 12 & 11.75 & 1.2 & 13.64 \\
\hline 4 & 3 & $S$ & 31.9 & 31.54 & 12.2 & 10.9 & 4.2 & 13.17 \\
\hline 5 & 4 & $\mathrm{~S}$ & 57.6 & 55.91 & 13.4 & 11.2 & 8.04 & 13.96 \\
\hline
\end{tabular}

\section{DISCUSSION}

The diagram below (Fig.3) illustrates the comparison of achieved values of the first experiment, showing inaccuracies in fuel consumption quantifications that occur mostly on the shortest route. In this case, these mistakes were caused by fuel foaming and the deviation of the pistol switch-off [18]. These faults emerge throughout the experiment, which seems to be the most significant on the shortest route. The inaccuracies appear due to the approximately equal deviation after refilling, however being the most material on the shortest circuit $(3.9 \mathrm{~km})$, where the influence on the calculated consumption is the greatest [19]. This fact is caused by fuel overflow through the tank cap.

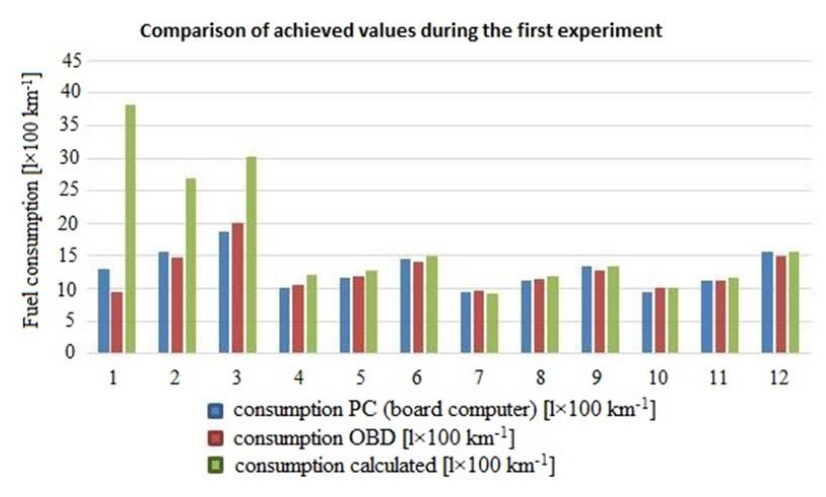

Fig. 3. Comparison of achieved values during the first experiment. Source: authors

Table 5 shows only a negligible difference between the consumption quantified by the Onboard computer and smartphone application $(1.61 \%)$, with respect to the ratio between the consumption and both experimental devices [20].
The most considerable deviation appeared during the experiment on the first route, requiring completion of the last row in the table, which compares anomalies without specifying the experimental track. These figures show a dramatic reduction in deviation values. The average rate of OBD apps with a deviation of $4.26 \%$ is the closest to the estimated consumption; nevertheless, it should further grow by $0.97 \%$ (the average deviation from the accuracy of the petrol pump BA 95), while taking into account pump pistol switchoff difference ranging from (+/-) 0.023 I.; i.e. the resulting inconsistency between the calculated consumption and smartphone application will be of $5.23 \%(+/-) 0.023$ l.

Table 5. Comparison of deviations of the first experiment Source: auhtors

\begin{tabular}{|c|c|c|c|c|c|c|}
\hline i & 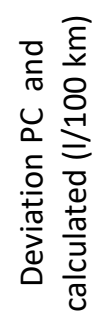 & 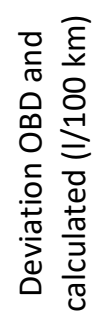 & 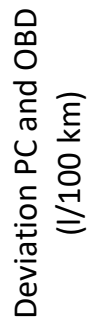 & 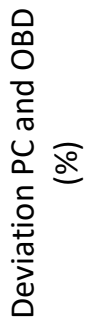 & 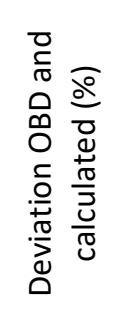 & 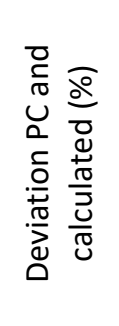 \\
\hline 1 & -25.16 & -28.66 & 3.50 & 26.92 & -301.66 & -193.52 \\
\hline 2 & -11.32 & -12.22 & 0.90 & 5.77 & -83.15 & -72.58 \\
\hline 3 & -11.46 & -10.16 & -1.30 & -6.91 & -50.53 & -60.94 \\
\hline 4 & -1.85 & -1.45 & -0.40 & -3.92 & -13.64 & -18.09 \\
\hline 5 & -1.13 & -0.83 & -0.30 & -2.59 & -6.95 & -9.72 \\
\hline 6 & -0.40 & -0.80 & 0.40 & 2.74 & -5.63 & -2.74 \\
\hline 7 & 0.19 & 0.39 & -0.20 & -2.11 & 4.02 & 2.00 \\
\hline 8 & -0.65 & -0.35 & -0.30 & -2.68 & -3.04 & -5.80 \\
\hline 9 & 0.08 & -0.72 & 0.80 & 5.93 & -5.65 & 0.62 \\
\hline 10 & -0.69 & 0.01 & -0.70 & -7.45 & 0.13 & -7.30 \\
\hline 11 & -0.45 & -0.35 & -0.10 & -0.89 & -3.09 & -4.01 \\
\hline 12 & 0.03 & -0.67 & 0.70 & 4.49 & -4.52 & 0.17 \\
\hline$\varnothing$ & -4.40 & -4.65 & 0.25 & 1.61 & -39.48 & -30.99 \\
\hline 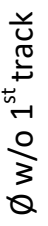 & -0.54 & -0.53 & -0.01 & -0.72 & -4.26 & -4.99 \\
\hline
\end{tabular}

The following diagram (Fig.4) depicts the average fuel consumption values of individual routes and their standard deviations for all the experimental techniques. The diagram illustrates the enormous influence of inaccuracies on the shortest experimental segment [21]. 


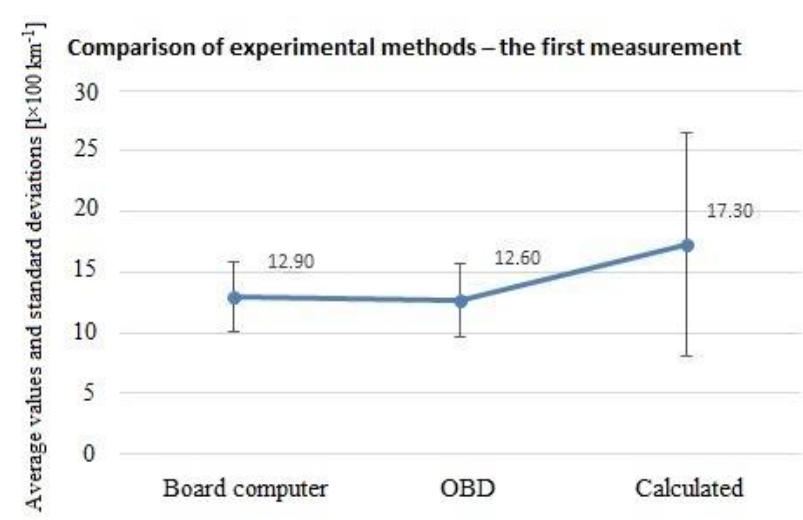

Fig. 4. Schematic comparison of individual experimental methods; the first measurement. Source: authors

The following figure (Fig.5) represents a comparison of detected values of the second investigation.

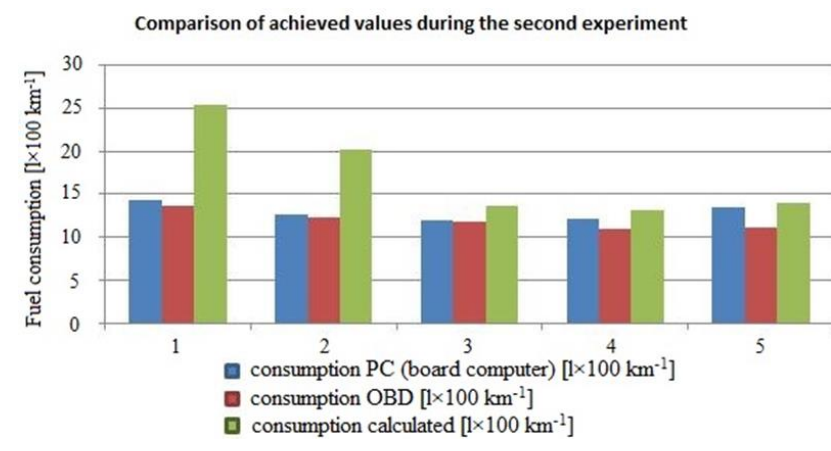

Fig. 5. Comparison of achieved values during the second experiment. Source: authors

The following statistics (see Table 6) summarize deviation values of the second measurement.

Table 6. Comparison of fuel consumption deviations of SI engine in the second experiment. Source: authors

\begin{tabular}{|c|c|c|c|c|c|c|c|}
\hline i & 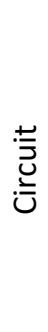 & 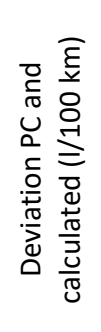 & 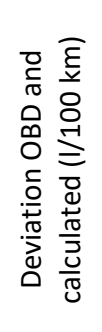 & 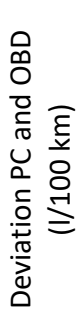 & 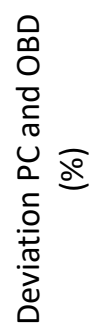 & 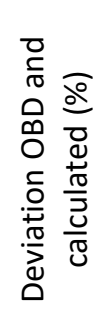 & 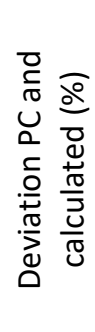 \\
\hline 1 & 1 & $-11,08$ & $-11,68$ & 0,60 & 4,20 & $-85,29$ & $-77,51$ \\
\hline 2 & 1 & $-7,56$ & $-7,96$ & 0,40 & 3,15 & $-64,69$ & $-59,50$ \\
\hline 3 & 2 & $-1,64$ & $-1,89$ & 0,25 & 2,08 & $-16,05$ & $-13,64$ \\
\hline 4 & 3 & $-0,97$ & $-2,27$ & 1,30 & 10,66 & $-20,79$ & $-7,92$ \\
\hline 5 & 4 & $-0,56$ & $-2,76$ & 2,20 & 16,42 & $-24,63$ & $-4,17$ \\
\hline 8 & $x$ & $-4,36$ & $-5,31$ & 0,95 & 7,30 & $-42,29$ & $-32,55$ \\
\hline$\varnothing v$ & $\begin{array}{l}v / \\
\text { st }\end{array}$ & $-1,05$ & $-2,73$ & 1,68 & 12,88 & $-24,22$ & $-8,26$ \\
\hline
\end{tabular}

In this case, the board computer (PC) showed higher accuracy with a deviation of $8.26 \%$. This experiment had to take into consideration an accuracy deviation of the petrol pump of $0.97 \%$ for petrol 95 octane. The anomaly resulting value is approximately $7.29 \%$ [22].

The following chart (Fig.6) illustrates mean (average) values and their standard deviations of each of the routes being examined.

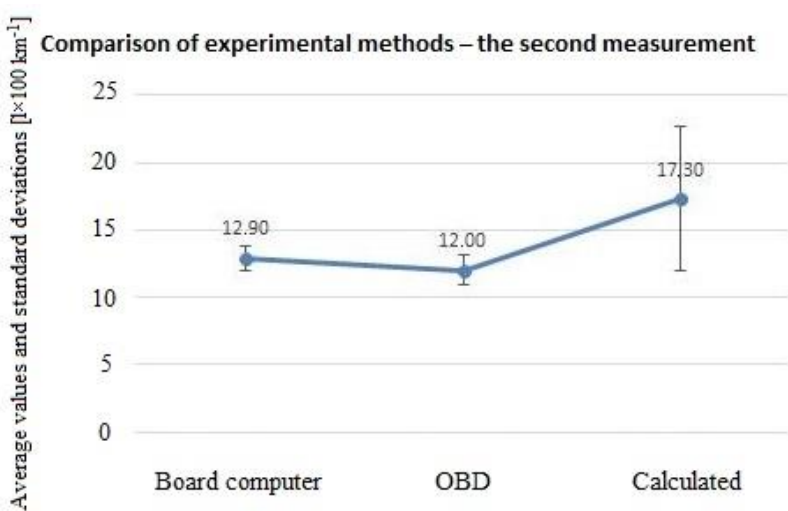

Fig. 6. Schematic comparison of individual experimental methods; the second measurement. Source: authors

\section{CONCLUSION}

The manuscript focused on searching for the most accurate daily-user method of detecting fuel consumption. The experiment aimed at recommending a convenient technique to achieve the specific objective using a car with the sparkignition engine AUDI S5. The vehicle underwent tests on four predesignated routes. Each circuit showed particular parameters such as length, speed limit, number of intersections with significant waiting time and the city/highway drive ratio. The specific technique of driving also affects the very fuel consumption. The experimental research comprised in total 12 journeys to meet this specification with each journey taken in three different forms on all four routes; standard, economical and dynamic mode as separate styles to a great extent impact on fuel consumption. The experiment implementation and resulting evaluation of fuel consumption followed three different approaches; calculation (quantification) method, the method of subtracting data from the on-board computer (PC) and OBD apps, which required the use of special measuring technology.

Apart from the fuel consumption experiment, the detection of the amount of consumed fuel and its deviation when automatically switching off the pump pistol constituted an integral part of the research. Resulting tables and detailed diagrams 
depict the evaluation of the amassed data. The findings recommended the use of the first of the adopted measurement (detection) methods, suggesting that the experiment may regard the deviation caused by the pump pistol automatic switch-off. Accuracy of this method is increasing by higher amount of consumed fuel or driven distance. This method is not suitable for fuel consumption calculation on short tracks (over $10 \mathrm{~km}$ ).

Repeated investigation and proper modification of vehicle drive style (technique) provides a dailyuser with more precise information on the fuel consumption of a specific vehicle.

Acknowledgement: Project VEGA No. 1/0128/20: Research on the Economic Efficiency of Variant Transport Modes in the Car Transport in the Slovak Republic with Emphasis on Sustainability and Environmental Impact, Faculty of Operation and Economics of Transport and Communications: University of Zilina, 2020-2022.

and

This manuscript was supported within solving the research project entitled "Autonomous mobility in the context of regional development LTC19009" of the INTER-EXCELLENCE program, the VES 19 INTERCOST subprogram.

\section{REFERENCES}

[1] J. Son, J. Ko, K. Kim, CL. Myung, S. Park, C. Kim, Correlation analysis of road load fuel economy variations by energy difference for gasoline direct injection and diesel-powered vehicles. Proceedings of the Institution of Mechanical Engineers, Part D: Journal of Automobile Engineering, Vol.234, 897-911, 2020.

https://doi.org/10.1177/0954407019899516

[2] L. Tribioli, R. Cozzolino, D. Chiappini, Technical Assessment of Different Operating Conditions of an On-Board Autothermal Reformer for Fuel Cell Vehicles. Energies, 10 (7), 2017: 839.

https://doi.org/10.3390/en10070839

[3] A. Roque, F. Foucher, Q. Lamiel, B. Imoehl, N. Lamarque, J. Helie, Impact of gasoline direct injection fuel films on exhaust soot production in a model experiment. International Journal of Engine Research, 21 (2), 2020: 367-390. https://doi.org/10.1177/1468087419879851
[4] C. Keramydas, G. Papadopoulos, L. Ntziachristos, TS. Lo, KL. Ng, HLA. Wong, CKL. Wong, Real-World Measurement of Hybrid Buses' Fuel Consumption and Pollutant Emissions in a Metropolitan Urban Road Network. Energies, 11 (10), 2018: 2569.

https://doi.org/10.3390/en11102569

[5] B. Sarkan, J. Caban, A. Marczuk, J. Vrabel, J. Gnap, Composition of exhaust gases of spark ignition engines under conditions of periodic inspection of vehicles in Slovakia. Przemysl Chemiczny, 96 (3), 2017: 675-680.

https://doi.org/10.15199/62.2017.3.36

[6] Y. Li, X. Duan, J. Fu, J. Liu, S. Wang, H. Dong, Y. Xie, Development of a method for on-board measurement of instant engine torque and fuel consumption rate based on direct signal measurement and RGF modelling under vehicle transient operating conditions. Energy, 189, 2019.

https://doi.org/10.1016/i.energy.2019.11621 $\underline{8}$

[7] P. Dekraker, M. Stuhldreher, Y. Kim, Characterizing Factors Influencing SI Engine Transient Fuel Consumption for Vehicle Simulation in ALPHA. SAE Int. J. Engines, 10(2), 2017: 529-540.

https://doi.org/10.4271/2017-01-0533

[8] J. Van Mierlo, G. Maggetto, E. van de Burgwal, R. Gense, Driving style and traffic measuresinfluence on vehicle emissions and fuel consumption. Proceedings of the Institution of Mechanical Engineers, Part D: Journal of Automobile Engineering, Vol.218, 43-50, 2004. https://doi.org/10.1243/09544070432282915 $\underline{5}$

[9] P. Drozdziel, S. Tarkowski, I. Rybicka, R. Wrona, Drivers' reaction time research in the conditions in the real traffic. Open Engineering, 10 (1), 2020: 35-47. https://doi.org/10.1515/eng-2020-0004

[10] Z. Matuszak, M. Jaskiewicz, D. Wieckowski, J. Stoklosa, Remarks to the Reliability Assessment and to Human Actions - Especially Car Driver, $18^{\text {th }}$ International Scientific Conference - LOGI 2017, Vol.134, 1-8, 2017. https://doi.org/10.1051/matecconf/20171340 $\underline{0036}$

[11] A. Polcar, J. Cupera, V. Kumbar, Calibration and its Use in Measuring Fuel Consumption with the CAN-Bus Network. Acta Univ. Agric. Silvic. Mendelianae Brun, 64 (2), 2016: 503-507. 
https://doi.org/10.11118/actaun20166402050 $\underline{3}$

[12] B. Sarkan, L. Holesa, J. Caban, Measurement of Fuel Consumption of a Road Motor Vehicle by Outdoor Driving Testing. Adv. Sci. Technol. Res. J., 7 (19), 2013: 70-74. https://doi.org/10.5604/20804075.1062374

[13] S. Narayn, S. Milojevic, V. Gupta, Combustion monitoring in engines using accelerometer signals. Journal of Vibroengineering, 21 (6), 2019, 1552-1563.

https://doi.org/10.21595/jve.2019.20516

[14] C. Csiszár, D. Földes, System Model for Autonomous Road Freight Transportation. Promet - Traffic \& Transportation, 30 (1), 2018: 97-103.

https://doi.org/10.7307/ptt.v30i1.2566

[15] J. Van der Krieke, G. Van Raemdonck, Analyzing Fuel Savings of an Aerodynamic Drag Reduction Device with the Aid of a Robust Linear Least Squares Method, SAE Int. J. Commer. Veh. 7 (2), 2014: 675-684

https://doi.org/10.4271/2014-01-2450

[16] G. Kovács, M. Gubán, Planning of Optimal Fuel Supply of International Transport Activity, Periodica Polytechnica Transportation Engineering, 45 (4), 2017: 186-195.

https://doi.org/10.3311/PPtr.10843

[17] M. Barth, K. Boriboonsomsin, Energy and emissions impacts of a freeway-based dynamic eco-driving system. Transportation Research Part D: Transport and Environment, 14 (6), 2009: 400-410. https://doi.org/10.1016/i.trd.2009.01.004

[18] M. Dziubinski, G. Litak, A. Drozd, J. Stoklosa, A. Marciniak, Modeling method embedded into diagnostics, reliability and maintenancemodels as knowledge representation systems, Second International Conference on Reliability Systems Engineering (ICRSE), Beijing, 2017, 15.

https://doi.org/10.1109/ICRSE.2017.8030716

[19] K. Köck, Real-World Fuel Consumption Measurement as the Base for the Compliance to Future $\mathrm{CO}_{2}$ Regulations, SAE Int. J. Adv. \& Curr. Prac. in Mobility, 1 (1), 2019: 157-165. https://doi.org/10.4271/2019-26-0357

[20] J. Ondruš, P. Kohút, R. Jurina, K. Brösdorf, How do Today's Modern Passenger Cars Brake?, LOGI - Scientific Journal on Transport and Logistics, 9 (1), 2018: 83-93.

https://doi.org/10.2478/logi-2018-0010

[21] G. Koszalka, J. Hunicz, A. Niewczas, A Comparison of Performance and Emissions of an Engine Fuelled with Diesel and Biodiesel. SAE Int. J. Fuels Lubr. 3 (2), 2010: 7784.

https://doi.org/10.4271/2010-01-1474.

[22] Z. Chłopek, J. Biedrzycki, P. Wójcik, P. Bukrejewski, M. Paczuski, M. Marchwiany, Performance of Internal Combustion Engine Fueled by Liquefied Petroleum Fuel with Water Addition. The Archives of Automotive Engineering - Archiwum Motoryzacji, 73 (3), 2016: 89-101.

https://doi.org/10.14669/AM.VOL73.ART6 